\title{
DIGITALCOMMONS
}

@WAYNESTATE-

Wayne State University

Civil and Environmental Engineering Faculty

Research Publications

Civil and Environmental Engineering

$5-21-2019$

\section{Development of Traffic Live Load Models for Bridge Superstructure Rating with RBDO and Best Selection Approach}

\author{
Sasan Siavashi \\ Wayne State University, sasan.siavashi@wayne.edu \\ Christopher D. Eamon \\ Wayne State University, eamon@eng.wayne.edu
}

Follow this and additional works at: https://digitalcommons.wayne.edu/ce_eng_frp

Part of the Civil Engineering Commons, and the Transportation Engineering Commons

\section{Recommended Citation}

Siavashi, S. and Eamon, C. D. 2019. "Development of traffic live load models for bridge superstructure rating with RBDO and best selection approach." J. Bridge Eng. 24 (8): 04019084. https://doi.org/ 10.1061/(ASCE)BE.1943-5592.0001457.

This Article is brought to you for free and open access by the Civil and Environmental Engineering at DigitalCommons@WayneState. It has been accepted for inclusion in Civil and Environmental Engineering Faculty Research Publications by an authorized administrator of DigitalCommons@WayneState. 
1 Development of Traffic Live Load Models for Bridge Superstructure Rating with RBDO

2 and Best Selection Approach

3 Sasan Siavashi ${ }^{1}$ and Christopher D. Eamon ${ }^{2}$

\section{Abstract}

5 Reliability-based design optimization (RBDO) is frequently used to determine optimal structural

6 geometry and material characteristics that can best meet performance goals while considering

7 uncertainties. In this study, the effectiveness of RBDO to develop a rating load model for a set

8 of bridge structures is explored, as well as the use of an alternate Best Selection procedure that

9 requires substantially less computational effort. The specific problem investigated is the

10 development of a vehicular load model for use in bridge rating, where the objective of the

11 optimization is to minimize the variation in reliability index across different girder types and

12 bridge geometries. Moment and shear limit states are considered, where girder resistance and

13 load random variables are included in the reliability analysis. It was found that the proposed Best

14 Selection approach could be used to develop rating model as nearly as effective as an ideal

15 RBDO solution but with significantly less computational effort. Both approaches significantly

16 reduced the range and coefficient of variation of reliability index among the bridge cases

17 considered.

18 Author Keywords:

19 Optimization, Reliability-based design optimization, Load rating, Load model

1. Ph.D. candidate, Department of Civil \& Environmental Engineering, Wayne State University, Detroit, MI, USA (corresponding author); sasan.siavashi@wayne.edu

2. Associate Professor, Department of Civil \& Environmental Engineering, Wayne State University, Detroit, MI, USA; eamon@eng.wayne.edu 


\section{Introduction}

Bridge load rating is required by the US Department of Transportation (DOT) to assure that structures within each state inventory are sufficiently safe for vehicular traffic. Bridge rating

28 procedures are specified in the Manual for Bridge Evaluation (MBE) (AASHTO 2018), where rating for design, legal, and permit loads is discussed. Generally, it is desired by the DOTs to limit bridge posting as much as possible, as restrictions prevent the general public, as well as commercial vehicles, from fully utilizing the transportation network. Typically, the design load rating evaluates the ability of the bridge to carry the HL-93 design load specified in the American Association of State Highway and Transportation Officials Load and Resistance Factor Design Specifications (AASHTO LRFD 2017) and is used to complete the Federal 35 inventory rating. The design load is also used to evaluate the bridge at the Federal operating level, where capacity associated with a lower level of reliability is assessed. Structures are also

37 rated for state-specific legal loads at the operating level, to determine if traffic restriction is required.

Since 2003, with the publication of the Manual for Condition Evaluation and Load and Resistance Factor Rating (LRFR) of Highway Bridges (AASHTO 2003), bridge rating has been

41 implicitly based on an assessment of structural reliability. The MBE was later released in 2008,

42 replacing the initial LRFR specifications as well as the alternative 1998 Manual for Condition

43 Evaluation of Bridges (based on Load Factor Rating, which was not reliability-based). The

44 purpose of the LRFR version was to provide a more consistent level of safety than that achieved

45 under the previous procedure. Part of the LRFR calibration effort was to develop appropriate

46 vehicular live load statistics used in the reliability assessment to establish live load factors for

47 rating. These factors were later revised in 2011 (Sivakumar and Ghosn 2011) using weigh-in- 
motion (WIM) data from truck traffic collected from six states. Based on a 5-year return period for load rating, the recalibrated MBE rating process was formulated to result in an average target reliability index $(\beta)$ of 2.5 , with a minimum level of 1.5 for any particular structure.

Although the WIM data collected to develop the live load factors in the MBE represented 52 a significant improvement in load modeling over previous versions, understandably, it does not necessarily well-represent the traffic loads in various other states that were not included in the MBE calibration effort. However, a number of states initiated efforts to develop unique live load models to better represent local traffic data. Some of these include Missouri (Pelphery et al. 2006), Oregon (Kwon et al. 2010), and New York (Ghosn et al. 2011; Anitori et al. 2017), where

57 state-specific WIM data were used to develop new live load factors for bridge design and rating.

58 Similar work includes that implemented by Texas (Lee and Souny-Slitine 1998) and Wisconsin

59 (Tatabai et al. 2009), which used WIM data to better characterize vehicle load effects.

61 rating procedure based on a reliability-based analysis of WIM data. It was found that use of 62 existing rating vehicles produced significant inconsistencies in reliability. That is, for a given 63 rating factor, one structure had a significantly different level of reliability than another. This 64 inconsistency varied depending on bridge geometry, girder material type, and mode of failure.

65 One way to resolve this problem would be to vary the live load factor on the rating vehicle as 66 necessary to match the required reliability level. However, this approach would be impractical, 67 requiring many hundreds of different load factors, one for each bridge type and geometry. An 68 alternative possible solution is to simply apply the largest live load factor required across all 69 cases, such that the minimum specified reliability level is always achieved. From the perspective 70 of the DOT, this simpler approach is highly undesirable, as it would result in a large number of 
71 under-rated structures, potentially leading to unnecessary traffic restriction. Because the pattern

72 of required load factor variation is complex, the development of an appropriate live load model

73 for rating is not obvious. For such problems, reliability-based design optimization (RBDO) may

74 be an appropriate solution approach.

In a typical RBDO procedure, geometric (or material) design parameters are taken as

76 design variables (DVs), where an optimal set is determined that best meets specified

77 performance criteria when subjected to reliability-based constraints. Various research efforts

78 have used this approach to optimize hypothetical bridge designs for different performance goals,

79 such as cost minimization (Thoft 2000; Turan and Yanmaz 2011; Behnam and Eamon 2013;

80 Saad et al. 2016; Garcia-Segura et al. 2017); weight (Nakib 1991; Yang et al. 2011; Thompson et

81 al. 2006), and resistance to extreme loads (Negaro and Simoes 2004; Basha and Sivakumar 2010;

82 Kusano et al. 2014).

83 In this study, rather than taking design variables as geometric characteristics of a bridge

84 to develop an optimal design, DVs are taken as representative parameters of the rating model

85 itself. That is, RBDO is not used to develop an optimal structural design, but rather an optimal

86 live load model to be used for bridge rating. As such, the first objective of this study is to

87 examine the viability of using RBDO to develop a rating live load model, with the objective to

88 minimize the inconsistencies in rating factor and corresponding reliability level among many

89 different types of bridge girders. Kamjoo and Eamon (2018) recently proposed a similar

90 approach for development of a load model for design.

Although an RBDO result may represent a theoretically ideal solution, it is accompanied

92 by several notable drawbacks: high computational cost, a somewhat complex problem

93 formulation, and a resulting load model that may bear little resemblance to any realistic vehicle 
94 configuration. Thus, the second, and primary objective of this study is to evaluate the

95 effectiveness of a simple and much less costly alternative approach which provides not an

96 optimal solution, but the best solution available based only on measured actual vehicle

97 configurations.

98

\section{Traffic Data Collection}

As noted above, various agencies have collected state-specific WIM data and have used

101 those data to refine bridge rating models. To evaluate the viability of the two approaches for

102 rating load model development considered in this study, traffic data collected from Michigan are

103 considered as an example. The WIM data used here were obtained from consideration of

104 approximately 40 Michigan stations with high-speed (1000 Hz) sampling necessarily to

105 accurately record vehicle configurations and positioning. Of these sites, a selection of 20

106 representative locations throughout the State were chosen in different average daily truck traffic

107 (ADTT) categories ranging from approximately 400 to 16000. These stations are generally on

108 major routes (State and Interstate roadways). The WIM data used were collected over 34 months

109 from February 2014 to January 2017, excluding April and May 2014, which were unavailable.

110 Since WIM data is often associated with collection errors, data filtering criteria were employed

111 to eliminate unrealistic records from the 101 million vehicle database, such as feasible

112 limitations on axle spacing, weight, speed, and length (for example, truck axles spaced closer

113 than $1 \mathrm{~m}$; heavy trucks with speeds over $160 \mathrm{kph}$; axle weights over $312 \mathrm{kN}$, etc.; see Eamon et

114 al. 2016 for a complete description of these criteria). To further confirm the reasonableness of

115 the WIM data, several checks were implemented as recommended in NCHRP 683, such as 
comparison of the gross vehicle weight (GVW) frequency histograms, mean and modal axle spacing, GVW, and axle weights to generally expected values (Eamon and Siavashi 2018). The database was then further reduced to consider only legal and routine (annual) permit vehicles, which MDOT groups together for Strength I limit state evaluation (i.e. normal use of the bridge) within the legal load rating framework. A summary of the criteria used to categorize a record as a legal or routine permit vehicle is given in Table 1. After applying the filtering criteria, about 89 million vehicle records remained and were considered for later load effect analysis, as described below.

\section{Reliability-Based Design Optimization}

Probability theory is most commonly used to model uncertainty in reliability-based design optimization. Correspondingly, an RBDO problem defines a set of $N D V$ design variables $\boldsymbol{Y}=\left\{Y_{1}, Y_{2}, \ldots, Y_{N D V}\right\}^{T}$ to be determined that minimizes or maximizes given performance criteria, as well as a set of $n$ random variables $\boldsymbol{X}=\left\{X_{1}, X_{2}, \ldots, X_{n}\right\}^{T}$ that describe load, resistance, and other uncertainties. Given a probabilistic limit state function $g(\boldsymbol{X}, \boldsymbol{Y})$ for consideration, failure can be defined as $g(\boldsymbol{X}, \boldsymbol{Y}) \leq 0$, and correspondingly, $g(\boldsymbol{X}, \boldsymbol{Y})>0$ implies safety while $g(\boldsymbol{X}, \boldsymbol{Y})=0$ represents the boundary between the failed and safe regions.

Various methods of formulating and solving RBDO problems have been proposed (Enevoldsen and Sorensen 1995; Tu et al. 1999; Rais-Rohani and Xie 2005; Kharmanda and Olhoff 2007; Aoues and Chateauneuf 2010, etc), including numerous approximate methods for assessing probabilistic constraints to reduce computational effort (Enevoldsen and Sorensen 1995; Tu et al. 1999; Du and Chen 2004; Qu and Haftka 2004). In this study, an RBDO approach is used to develop a live load rating model that should result in a requirement for traffic 
139 restriction to occur on any structure when it reaches a minimum specified level of reliability. In

140 other words, the variation in reliability level among different structures, at the point at which

141 traffic restriction is imposed, is minimized (ideally zero).

142 With this approach in mind, the optimization problem is described as:

$$
\min f(\boldsymbol{X}, \boldsymbol{Y})
$$

where $f(\boldsymbol{X}, \boldsymbol{Y})$ is an objective function quantifying variability in structural reliability among the

151 index; and $Y_{k}$ is the $k^{\text {th }}$ design variable among $N D V$ design variables, with lower and upper

152 bounds given as $Y_{k}^{l}$ and $Y_{k}^{u}$.

153 As discussed earlier, objective functions for bridge-related RBDO problems have been most 154 commonly expressed in term of weight or cost, such that these performance measures can be 155 minimized. Here, the desire is to minimize variation in reliability among different girders, and 156 thus $f(\boldsymbol{X}, \boldsymbol{Y})$ must be formulated to quantify this variation. It follows that if all girders match the 157 desired reliability index at the same reference value for rating factor, variation from the target 158 reliability level $\left(\beta_{T}\right)$ is zero and an ideal solution results. Variation from a target level can of 159 course be quantified in numerous ways, such as mean squared error, root mean squared error, R- 
squared, mean absolute error, and many others. Mean squared error is used in this study, which results in an objective function formulated as:

$$
f(X, Y)=\sum_{i=1}^{N_{p}} \frac{\left(\beta_{i}-\beta_{T}\right)^{2}}{N_{p}}
$$

\section{Reliability Analysis}

Random variables $\boldsymbol{X}$ used for reliability assessment are girder resistance $(R)$ and load effects, the latter of which include vehicle live load $(L L)$, dynamic load $(I M)$, and dead load from prefabricated $\left(D_{p}\right)$ and site-cast $\left(D_{s}\right)$ components, as well as from the deck wearing surface $\left(D_{w}\right)$. Uncertainty in the distribution of vehicular live load to an individual girder is also considered $(D F)$. Bias factor (ratio of mean to nominal value) and coefficient of variation (COV) for random variables are given in Table 2. With the exception of live load $(L L)$, which is calculated from Michigan-specific data, all random variable statistical parameters are based on those used in the AASHTO LRFD (Nowak 1999) and MBE calibrations (AASHTO 2018). For reliability assessment, girder resistance is considered lognormal whereas the sum of load effects is taken as normally distributed, as assumed in previous calibrations for consistency (Nowak 1999; Sivakumar et al. 2011).

As reported by Eamon and Siavashi (2018), vehicular live load statistics were developed from the 89 million records of WIM data collected from Michigan as described above, where load effects were calculated by incrementing trains of measured vehicles across various hypothetical bridge spans from 6-60 $\mathrm{m}$ and recording maximum moment and shears. In this process, the total load effect to a girder caused by the actual vehicle locations relative to oneanother in single and adjacent lane placements were maintained. Live load effects were 
182 proportioned to the girder based on mean values of $D F$, where nominal values are specified in

183 AASHTO LRFD as a function of bridge geometry. Vehicle live load is then projected to an

184 assumed 5-year rating period as specified in the MBE (corresponding to the maximum assumed

185 time between inspections) for legal and routine permit rating, using an Extreme Type I

186 extrapolation, which was found to well-fit the Michigan data (Eamon et. al 2016). These live

187 load effects were found to have significant variation from the existing Michigan as well as MBE

188 rating models, as shown by the varying bias factor and COV for $L L$ in Table 2. In particular, a

189 bias factor of unity and COV of zero would indicate that the mean maximum value for live load

190 exactly matches the load effect caused by the existing (Michigan) rating model with no

191 uncertainty. As noted earlier, this difference was identified as the cause of the significant

192 discrepancy in girder rating reliability on Michigan bridge structures (Eamon and Siavashi

193 2018).

194 Once random variables are defined, the general limit state function $g$ for each bridge

195 girder $i$ can be written as:

196

$$
g_{i}=R-\left(D_{p}+D_{s}+D_{W}\right)-D F(L L+I M)
$$

with random variables $R, D_{p}, D_{s}, D_{w}, D F, I M$, and $L L$ defined above. Limit states are

198 formed for simple span load effects (moment and shear) for prestressed concrete I-shaped

199 girders, composite steel girders, reinforced concrete girders, and spread and side-by-side

200 prestressed concrete box beams. Bridges are assumed to support a reinforced concrete deck and

201 have a wearing surface and additional items such as barriers and diaphragms relevant for dead

202 load calculation. Dead loads are based on those used in the MBE calibration (NCHRP 683).

203 Bridges are taken as two lane, with span lengths from 6-60 meter in increments of $6 \mathrm{~m}$ (limited

204 to $30 \mathrm{~m}$ for reinforced concrete). Girder spacing varied from 1.2 to 3.6 meter at $0.6 \mathrm{~m}$ 
205 increments, while for side-by-side box beams, two widths (0.9 meters and 1.2 meters) were

206 considered. Thus, considering all combinations of length (10) and girder spacing (5)

207 increments results in 50 geometries each for prestressed concrete, steel, and spread box beam

208 bridge types; 25 for reinforced concrete; and 20 side-by-side box beams, for 195 cases. The

209 range of these geometries and types covers nearly all girder bridges in the state inventory.

210 The target reliability index associated with the MBE is $\beta_{T}=2.5$, which represents the

211 average required reliability level across all girders considered (AASHTO 2018). Although

212 during the MBE calibration the reliability index of any particular girder was allowed to fall as

213 low as 1.5 , this represents a very low level of nominal reliability that not all DOTs may be

214 comfortable with $\left(\beta=2.5\right.$ corresponds to failure probability $p_{f} \approx 1: 160$ whereas $\beta=1.5$

215 corresponds to $p_{f} \approx 1: 15$, an order of magnitude of difference; however, these reliability targets

216 are notional values and corresponding failure probabilities should not be taken literally). In this

217 study, a higher minimum level is imposed such that the minimum $\left(\beta_{\text {min }}\right)$ as well as the target $\left(\beta_{T}\right)$

218 indices are taken as 2.5 , although this creates a more challenging problem for the solution

219 methods considered to address.

To establish nominal values for girder resistance for use in the reliability analysis, the

221 minimum requirements of acceptability must be identified, to avoid biasing reliability results

222 upward by analyzing conservatively-designed components. For example, in the case of design,

223 for LRFD in general, this criteria is expressed as: $\phi R_{n}=\sum \gamma_{i} Q_{i}$, (where $\gamma_{i}$ are load factors and $Q_{i}$

224 are load effects), and thus the minimum acceptable value for $R_{n}$, which is to be used in the

225 reliability analysis, can be established if load effects $Q$ are known. 
227 minimum acceptable value (i.e. without requiring traffic restriction) is 1.0. Rating factor (RF) is

228 given in the MBE by:

$$
R F=\frac{\phi R_{n}-1.25 D C-1.5 D W}{\gamma_{L L}(L L+I M)}
$$

230

231

232

233

In this expression, resistance factor $\phi$ varies as a function of girder type and failure mode; $R_{n}$ is the nominal resistance of the component; $D C$ and $D W$ are the dead loads of the structure and the wearing surface, respectively; $I M$ is specified as $1.33, L L$ is the rating vehicle live load effect, and $\gamma_{L L}$ is the rating vehicle load factor.

To meet the required reliability level, the rating vehicle must produce a live load effect $(L L)$ that produces $\beta_{T}=2.5$ when $\mathrm{RF}=1.0$. Thus, setting $\mathrm{RF}=1.0$ and solving for the required $R_{n}$ results in:

$$
R_{n}=(1 / \phi)\left(1.25 D C+1.5 D W+\gamma_{L L}(L L+I M)\right)
$$

which is the minimum nominal resistance for consideration in reliability rating. Here it should be noted that $R_{n}$ from Eq. 5 represents a notional, or theoretical resistance, used for evaluation of the reliability level associated with the rating process, and does not necessarily represent the resistance of an actual girder. This is analogous to the standard practice of evaluating components with resistance set just equal to the design limit for reliability assessment of design code specifications, even though actual components are typically over-designed (Nowak 1999). Considering Eq. 5, if dead load and live load effects are known, $R_{n}$ can be established. With $R_{n}$, known, the mean value $\bar{R}$ of the girder resistance random variable $R$ can be determined using the bias factors $\lambda$ shown in Table $2\left(\bar{R}=\lambda \times R_{n}\right)$, and then the reliability index of the limit 
247 state in Eq. 3 computed. In this study, however, for which an optimal live load model is to be

248 determined, the total live load effect produced by the rating model $\left(\gamma_{L L}(L L+I M)\right)$ is unknown. It

249 can be found by setting $\beta_{T}=2.5$, then determining the minimum value of $\gamma_{L L}(L L+I M)$ needed to

250 produce an $R_{n}$ (and in particular, the mean value of $R$ ) that will satisfy the reliability target. For

251 convenience, in this study, the quantity $\gamma_{L L}(L L+I M)$ is referred to as the required load effect

252 (RLE); i.e. the total load effect required by the live load rating model such that $\beta=2.5$ when

$253 \mathrm{RF}=1.0$.

In summary, the reliability process is as follows. First, nominal and mean (using the bias

255 factors given in Table 2) values for dead load random variables $\left(D_{p}, D_{s}, D_{w}\right)$ and live load

256 distribution factor $(D F)$ are calculated from a selection of typical bridge designs used in previous

257 reliability-based calibration efforts as described above. Next, the mean value of $R$, needed for

258 reliability analysis, is expressed as the function: $\bar{R}=\lambda$ x $R_{n}$, where $R_{n}$ is given by Eq. 5 and bias

259 factor $(\lambda)$ given in Table 2 for the type of girder and failure mode considered. Note that $R_{n}$, and

260 hence $\bar{R}$, remains a function of the unknown $\operatorname{RLE}\left(\gamma_{L L}(L L+I M)\right)$. Then, reliability index is set to

261 the target level (2.5), and its evaluation is expressed as a function of the random variables $\left(R, D_{p}\right.$,

$262 D_{s}, D_{w}, D F, I M$, and $\left.L L\right)$ discussed above, considering the limit state function given by Eq. 3 . In

263 this calculation, mean girder resistance $\bar{R}$ remains a function of the unknown RLE. In the

264 calculation of $\beta$, since reliability index is preset to a known value, the only unknown is the RLE,

265 which is solved for. Thus, the live load effect needed to be produced by the rating live load

266 model (RLE) in order to meet the minimum reliability target can be determined.

A multitude of methods are available to assess the reliability index $\beta_{i}$ of the limit state

268 function (Eq. 3), the result of which is used in Eqs. 1 and 2. As optimization generally involves

269 many iterations, the computational cost of each cycle becomes an important factor in the 
270 feasibility of the RBDO process. For the particular problem considered here, approximately 195

271 reliability constraints for moment or shear must be evaluated at every optimization cycle (one for

272 each bridge type and geometry considered, as given above). Additionally, reliability index must

273 be computed twice for each girder to determine whether the governing load effect is generated

274 by vehicles in a single lane or in both lanes. This process thus requires nearly 800 calculations of 275 reliability index for each optimization iteration.

276 One approach that allows reliability index to be quickly computed is the First Order,

277 Second Moment (FOSM) method, as a closed-form function of the means and standard

278 deviations of random variables. Although its small computational demand is ideal for RBDO,

279 FOSM does not provide exact solutions for limit state functions that are algebraically nonlinear

280 or composed of non-normal random variables. This is problematic in this study because girder

281 resistance $R$ is taken to be lognormal, which will produce a conservative estimate of $\beta$ if FOSM

282 is used. The degree of conservatism using FOSM with the limit state functions and random

283 variables considered here was investigated by Eamon et al (2014), where it was found that the

284 error in FOSM from the exact solution is consistent at a given level of reliability. That is,

285 regardless of bridge geometry or girder type, the FOSM approach produced a reliability index

286 with a consistent level of conservativeness from the exact value. For the target reliability index

287 used in this study $\left(\beta_{T}=2.5\right)$, the ratio of the exact value to the FOSM solution was found to be

288 approximately 1.04. Therefore, in this study, the FOSM method is used with the modification

289 suggested by Eamon et al. (2014), where the solution is adjusted by the factor of 1.04 when the

290 target reliability index constraint of 2.5 is imposed in the optimization. It should be emphasized

291 that this adjustment is valid only for the specific limit state functions and random variable

292 parameters used in this study. For other reliability problems, either a more general but costly 
293 approach must be used, such as FORM, the First Order Reliability Method (Rackwitz and

294 Fiessler 1978), or a new FOSM adjustment factor developed. For verification, a sample of girder

295 reliability indices were computed with Monte Carlo Simulation (MCS) with $1 \times 10^{6}$ simulations at

296 the completion of the RBDO. It was found that the indices estimated with the modified FOSM

297 approach described above were within 1\% of the "exact" MCS values.

298 Design Variables

299

As noted above, design variables within previous RBDO procedures applied to bridges

300

301

302

303

304

305

306

307

308

309

310

311

312

313

314

315 were used to describe geometric and potentially material properties. In this study, however, the optimization concerns a rating load model rather than a structural configuration. As such, design variables must describe critical parameters that define the load model. The existing nominal vehicular load rating model given in the MBE is the governing case of three trucks (Types 3, 3S2, and 3-3; see Figure 1), with a load factor of 1.35. As noted above, to account for local vehicle load requirements, which may higher than the federal standard, some states such as Michigan have increased this rating load. In particular, MDOT specifies 28 vehicles with different load factors for rating, which are meant to model possible legal configurations (MDOT 2005). Of these rating trucks, those that provided the maximum load effects for the spans considered in this study are given in Figure 2. As noted above, use of this existing MDOT rating model, as well as that given by the MBE, produced highly inconsistent girder reliabilities in rating (Eamon and Siavashi 2018).

A simple way that design variables could be used to develop a live load model is to use these parameters to describe a particular rating truck configuration. That is, the number of axles, axle spacing, and axle weights could be taken as design variables in the optimization. Although simple, this approach is somewhat constraining and does not fully utilize the potential of the 
RBDO process, as a single rating truck may not provide a good representation of the actual load

317 effects measured across all bridge spans. That is, the load effects that can be generated by a

318 rating truck are not nearly as flexible as load effects that can be generated by other means, such

319 as various mathematical functions not necessarily linked to the physical representation of a

320 single vehicle. This increased flexibility is potentially important because the load effect

321 generated by the rating model must not only account for the effects of single vehicles, but also

322 for load effects caused by multiple following vehicles in one lane, as well as groups of side-by-

323 side vehicles in two lanes, all of which contributed to the development of the live load random

324 variable $(L L)$ statistics shown in Table 2. Thus, the mean maximum live load effect used in the

325 reliability analysis is the result of a complex pattern of traffic loads as a function of bridge span,

326 which may be difficult to well-represent by a single rating vehicle.

Therefore, to allow the optimizer the greatest possibility to reach an ideal rating model with minimal variation in reliability (and thus minimize the objective function given by Eq. 2), design variables are not used to describe a physical representation of a rating vehicle, but rather to directly describe the required live load effect (RLE) caused by a rating vehicle, as a function 331 of bridge span. As defined above, the RLE refers to the total live load effect that must be 332 imposed on the structure in the rating process in order to meet the specified reliability target. Prior to the optimization, a preliminary evaluation was done by fitting various expressions to a selection of RLE values corresponding to different span lengths. This goodness of fit should give a reasonable indication of how successful the curve could be used in the optimization, as if the sample of RLEs can be well matched, then variation in reliability index

337 should be able to be well minimized in the RBDO. The curves considered included polynomial, 338 logarithmic, power, compound, logistic, growth, exponential, and sum of sines functions. Using 
root mean square error as a metric, it was found that a sum of sines function, similar to a Fourier series, could best fit the required rating load effect, and is given as:

$$
R L E=\sum_{i=1}^{n} a_{i} \sin \left(b_{i} x+c_{i}\right)
$$

where for $n$ terms, constants $a_{i}, b_{i}$, and $c_{i}$ represent design variables to be determined in the optimization and $x$ is bridge span length. Because the variation in RLE with respect to moment was found to be substantially different from that of shear, the analysis was conducted separately for shear and moment load effects to maximize the goodness of fit that could be obtained in each case. It was found that for both moment and shear, 3 terms are sufficient for describing required load effects, producing 9 design variables for load effects. Note that Equation 6 is not only significantly more flexible in generating RLE than a single rating truck, but it is also practically less complex in the RBDO. For example, a single 5-axle rating truck would also require up to 9 design variables to describe axle weights and spacing (5 variables for axle weights and 4 for spacing), as well as accompanying expressions needed for conversion of the truck configuration to maximum moment and shear load effects on a given span. Although this study is limited to simple span structures, it was found that the sum of sines function could similarly best fit the variation in RLE required for two-span continuous bridges. However, this would likely require development of a separate optimized load model for best results.

\section{Lower $\left(Y_{k}^{l}\right)$ and upper $\left(Y_{k}^{u}\right)$ bounds for the design variables (i.e. constants within Eq. 6)} are specified to be from $-100000 \leq Y_{k} \leq 100000$. Although not reached in the final results, the limits are important as they influence the generation of design variable values during each iteration of the optimization, as discussed in the section below. 
In the optimization, the RLE within Eq. 5 (i.e. the quantity $\gamma_{L L}(L L+I M)$ ) is taken as a

function given by Eq. 6, with design variables $a_{i}, b_{i}$, and $c_{i}(i=1-3)$. Following the reliability

procedure described above, Eq. 5 in turn determines $R_{n}$, which then affects the calculation of girder reliability. Therefore, in one cycle of the RBDO, trial values for design variables $a_{i}-c_{i}$ are found, then the RLE, $R_{n}$, and finally reliability index for all girders is computed. The objective function (Eq. 2) is then evaluated. Based on the results of Eq. 2, which quantifies the inconsistency in reliability for different girders, the optimizer determines new trial values of the design variables, in an attempt to minimize Eq. 2.

\section{Solution of RBDO Problem}

A simple RBDO approach typically requires two iterations; one iteration, the primary 'outer' loop, involves the optimizer, while the 'inner' nested loop concerns the reliability algorithm. In each cycle of the optimization, the objective function (Eq. 2) and reliability constraints $\left(\beta_{\min }=2.5\right)$ are evaluated based on the current design variable $\left(a_{i}, b_{i}, c_{i}\right)$ values, and based on these results, design variable values are updated for use in the next iteration. To update these values, each optimization iteration requires multiple evaluations of the objective function, while if an iterative reliability algorithm is used, multiple evaluations of the limit state function are also required. Thus, the double-loop procedure demands high computational effort.

The most common ways to reduce this effort are focused on modifying the interaction of the optimization and reliability algorithms (Kharmanda et al. 2002; Chen et al. 2002; Yang and Gu 2004; Mohsine et al. 2006), or directly increasing the efficiency of the reliability method by using approximate, direct methods in lieu of iterative-intensive approaches (Kirjner-Neto et al. 1998; Grandhi and Wang 1998; Koch and Kodiyalam 1999; Choi and Park 2001; Young and Choi 2004; Zou and Mahadevan 2006; Agarwal et al. 2007). As noted above, in this study, the 
383 later approach is used where computational efficiency is improved by using a non-iterative

384 reliability algorithm, modified for accuracy, thus eliminating the inner iterative loop in the 385 RBDO.

As with reliability algorithms, numerous optimization solution procedures are available.

387 One approach is to use a gradient-based solver such as sequential quadratic programming or the 388 modified method of feasible directions (Soler et al. 2012; Vanderplaats 1999). With these 389 methods, gradients of the objective function are taken with respect to the design variables, then 390 this information is used to determine new design variable values for the next iteration cycle. A 391 different approach to optimization is represented by heuristic methods, which often use a form of 392 probabilistic simulation in lieu of computing numerical derivatives. Some of these methods 393 include Simulated Annealing (Kirkpatrick 1984), Insect Colony Optimization (Karaboga and 394 Georgiou 1994), Genetic Algorithm (Koumousis and Georgiou 1994), and Particle Swarm 395 Optimization (Kennedy 2011). In this study, a genetic algorithm (GA) is used, which the authors 396 found to be an effective method in consideration of alternatives used in previous work (Behnam 397 and Eamon 2013; Thompson et al. 2006; Rais-Rohani et al. 2010). 399 objective function. At each iteration, new design variable values are determined with directed 400 probabilistic simulation. In general, the process starts with a large set of randomly generated 401 possible solutions (i.e. sets of design variable values), which are refined at each cycle by 402 evaluating how effectively the objective function is satisfied. New potential solutions are 403 generated from the most successful previous solutions until an optimal set is found. To generate 404 new solutions, for each successive iteration, two primary procedures, crossover and mutation, are 405 used. In the crossover procedure, subparts of two randomly selected previous solutions are 
combined to form a new solution, whereas the mutation procedure applies random changes to

407 randomly selected individual solutions. The purpose of these operators is to retain potentially

408 effective solutions while avoiding convergence to a local rather than global optimum (Man et al.

409 1996; Tang et al. 1996; Konak et al. 2006; Hao and Xia 2002).

In this study, a possible solution refers to a set of design variable values that represent

411 the values of the constants $\left(a_{i}, b_{i}, c_{i}\right)$ given in Eq. 6. The optimization starts by determining

$4121 \times 10^{6}$ possible solutions with Monte Carlo Simulation (MCS), using uniform distributions bound

413 by the limits $Y_{k}^{l}$ and $Y_{k}^{u}$ given above. This solution set size remains constant for all iterations.

414 Once this initial set of solutions is generated, the objective function (Eq. 2) is evaluated using all

415 of the potential solutions, and these results are recorded. The next iteration begins by generating

416 a refined set of solutions from several different sources: 1) 80\% are obtained by randomly

417 choosing two solutions from the previous set and producing a new solution by taking a weighted

418 average of these two solution values, such that the more effective solution (that with the lowest

419 objective function value) is given proportionally more weight (crossover); 2) the top 10\% of

420 most effective solutions are retained from the previous iteration; 3) 9.8\% are obtained from

421 MCS, as with the initial set; 4) $0.2 \%$ are obtained by randomly choosing a solution from the

422 previous iteration, then randomly choosing one of its design variables and replacing that value

423 with a new, randomly generated value using the MCS process (mutation).

424 The objective function is then evaluated with this new set of potential solutions, and the

425 process repeats during subsequent iterations until the solution converges. Here, convergence

426 implies that additional iterations cannot produce a more optimal solution than that found in

427 previous iterations; i.e. that the objective function cannot be further minimized. 


\section{Best Selection Approach}

As will be discussed in the Results section, the optimization procedure described above can produce an excellent load model with very low variation in required load effect across the

432 different bridge spans. However, although an RBDO result may represent a theoretically ideal 433 solution, it is accompanied by several notable drawbacks: high computational cost, a somewhat 434 complex problem formulation, and a resulting load model that may bear little resemblance to a 435 realistic vehicle. In this study, an alternative approach is examined where rather than generate an 436 idealized load model by optimization, a set of truck records from the WIM data that produce the 437 least variation from the RLE across all spans and bridge types is formed. Then, an appropriate 438 load factor is chosen for each record in the set such that the RLE is provided for all bridge spans, 439 ensuring that the imposed minimum required reliability requirement of $\beta_{\min }=2.5$ is met. The 440 resulting vehicle that has the least variation in RLE once the load factor is applied is then chosen;

441 i.e. the 'best' available selection. This best selection approach represents a simpler and vastly 442 less computationally costly solution than that obtained from the RBDO. The implementation 443 details and effectiveness of this approach are discussed below.

The first step in this process is to select a set of initial trucks for further consideration.

445 The amount of WIM data available for load model development is typically large. The database 446 used for this study, for example, as noted above, contains 89 million legal and routine permit 447 vehicle records, and full consideration of all vehicles in this set is costly. A much smaller subset 448 of these vehicles can be selected for further consideration by comparing the range of ratios of 449 load effect produced by the vehicle to that required (RLE) across the bridge spans considered. 450 Vehicles are selected based on a range of provided to required load effect ratios. This selection 451 limit can be expressed as: 
453 where $\left(\frac{V L E}{R L E}\right)_{\max }$ and $\left(\frac{V L E}{R L E}\right)_{\min }$ are the largest and smallest ratios of the vehicle load effect (VLE)

454 to the required load effect (RLE), respectively, found across the bridge spans considered, and $k$ is

455 the fractional range limit imposed. It was found that a VLE/RLE range of approximately $10 \%$

456 (i.e. $k=0.10)$ provides a reasonable selection of vehicles for further consideration. In this study, 457 using $k=0.10$ reduced the initial database of 89 million to about 2.2 million.

Although it may appear intuitive to do so, this first step does not simply select the vehicle

459 with the single lowest range of (VLE/RLE); i.e. that which would seemingly produce the lowest

460 discrepancy in reliability across the bridge spans considered. The reason for this is that the

461 appropriate load factors are not yet known for the initial vehicles considered. Any vehicle taken

462 from the WIM data, such as that which initially shows the lowest variation in VLE/RLE ratio,

463 will require a load factor such that its total load effect at least meets the RLE across all bridge

464 spans. However, when this load factor is imposed, it alters the range of (VLE/RLE) ratios,

465 sometimes substantially. This frequently results in a vehicle which initially had the lowest

466 (VLE/RLE) range to no longer having the lowest (VLE/RLE) range after the load factors are

467 applied. This occurs because imposing higher load factors (such as required on lighter vehicles)

468 magnifies the range of (VLE/RLE). This was found to be a nearly linear effect, where imposing

469 a load factor of 2 would generally double the (VLE/RLE) range. This can be seen in Figure 3,

470 which shows two trucks taken from the WIM data used in this study. Before load factors are

471 applied, Truck 2 has the lowest range of (VLE/RLE) from spans of 6-61 m. However, after

472 applying the required load factors to meet the RLE (1.60 for Truck 1 and 15.01 for Truck 2), the

473 (VLE/RLE) range of Truck 1 is lowest. As noted above, setting the selection limit $k$ at 0.10 
474 provided best results as a balance between computational effort and potential for selecting the

475 best solution. Increasing $k$ beyond about 0.1 was found to result in too many unnecessary

476 selections that are highly unlikely to be the optimal solution, needlessly increasing computational

477 effort. Conversely, lowering $k$ much more than about 0.1 was found to eliminate potentially

478 optimal solutions.

479 After required load factors are applied, the next step is to determine the metric used for 480 best selection. One possible metric would simply be the range of factored vehicle load effect

481 (VLE $)$ to RLE: (VLE $/$ RLE), where the vehicle with the lowest range would be selected.

482 However, the upper value of this range, $\left(\mathrm{VLE}_{\mathrm{f}} / \mathrm{RLE}\right)_{\max }$, may be governed by an outlier, a single,

483 particularly high result generated by a single bridge span. In this case, it may be more desirable

484 to select a vehicle that minimizes the amount of discrepancy among all bridge spans. Various

485 metrics of this nature are available. In this study, coefficient of variation (COV) is used for this

486 purpose. The final step is then to compute the selection metric for all vehicles in the set and

487 select the best result. In this case, $\mathrm{COV}$ of (VLE $\mathrm{f} / \mathrm{RLE})$ was computed for all vehicles in the set,

488 and that with the lowest value was taken as the best selection.

489

In summary, the proposed approach is as follows:

491

1. Select a target reliability index $\beta_{T}$ and compute corresponding required load effects

492 the "Reliability Analysis" section above. Note that although setting up the problem for the first

493 time may involve effort, once the process is programmed, obtaining the solution (i.e. the RLEs)

494 requires negligible computational time.

2. Compute the vehicle selection ratio given by the left side of Eq. 7 for all vehicle

496 records in the WIM database. Note that the vehicle load effects (VLEs) within Eq. 7 should be 
497 readily available, since VLEs are needed for development of any reliability-based load model,

498 and would have been used to characterize vehicle live load as a random variable prior to the

499 reliability analysis (for example, see Eamon et al. 2016). Since Eq. 7 is very simple

500 algebraically, it requires relatively small computational effort, even when many millions of

501 vehicles are considered

502 3. For the set of trial vehicles that have selection ratios less than $k=0.1$ (i.e. that satisfy

503 Eq. 7), for each vehicle, determine the load effect factor $\gamma_{F}$ necessary for the VLE to match the

504 RLE of each considered girder. This is simply the RLE divided by the VLE: $\gamma_{F}=$ RLE/VLE.

505 Then, apply the governing load effect factor $\gamma_{G F}$ among all girders for that vehicle to its VLE to

506 produce the factored VLE: VLE $=$ VLE $\times \gamma_{G F}$.

507 4. For each vehicle in the set of trial vehicles found in step 3, compute the COV of the

508 (VLE $/ \mathrm{RLE}$ ) ratios for each bridge girder considered. The result with lowest COV represents

509 the final, Best Selection vehicle to be chosen for the rating model. Note that the actual live load

510 factor required for MBE-based load rating $\left(\gamma_{L L}\right)$ using this vehicle can be easily recovered by

511 setting the total imposed load effect $\left(V_{L E}\right)$ equal to the denominator of Eq. 4, and solving: $\gamma_{L L}=$

$512\left(\mathrm{VLE}_{\mathrm{f}} /(L L+I M)\right)$, where in this case $L L$ represents the unfactored Best Selection vehicle load

513 effect. Since $\mathrm{VLE}_{\mathrm{f}}$ and $L L$ vary with span, the maximum $\gamma_{L L}$ across all spans is chosen in

514 practice.

515 This process is summarized in Figure 4.

517 Results

Following the RBDO approach, because variation in girder reliability (as a function of 519 spacing and span) with respect to moment was found to be substantially different from that of 
520 shear, the analysis was conducted separately for shear and moment load effects to maximize the 521 goodness of fit that could be obtained in each case. These results are calculated considering the

522 database of 195 hypothetical girder bridge designs of prestressed concrete I and box-shapes,

523 composite steel, and reinforced concrete, as discussed in the Reliability Analysis section above.

524 This results in two rating vehicles (models) from the procedures considered (RBDO and Best

525 Selection), one each for moment and shear effects, as compared to three existing AASHTO

526 rating trucks and 28 existing MDOT rating trucks for both moment and shear. For the RBDO,

527 the optimal results were obtained with approximately 500 iterations. For each load effect result

528 (moment and shear), the Best Selection approach was completed in approximately 17 minutes on

529 a modern desktop computer (with an Intel i7 $2.7 \mathrm{GHz}$ processor and $32 \mathrm{~GB}$ of RAM), while the

530 traditional RBDO process described requires approximately 14 hours of computational effort, an

531 increase in computational effort of nearly 50 times. Note that further reductions in computational

532 effort are likely possible with the use of more sophisticated algorithms and procedures. For

533 example, replacing the GA optimizer with a gradient-based solver may allow for greater

534 efficiency. However, such choices have possible drawbacks as well, such as finding local rather

535 than global minimums and potential convergence difficulties.

The final set of values obtained for the parameters of Eq. 6 are shown in Table 3, while

537 the trucks obtained from the Best Selection Approach are given in Figure 5. In Figure 6, the ratio

538 of the factored vehicle load effect to the required load effect (VLE $/$ RLE) for rating moment

539 effect is given. In the figure, results are shown for the RBDO solution, the Best Selection Truck,

540 and the MDOT and AASHTO rating trucks, once required load factors are applied such that all

541 truck models meet the minimum RLE (i.e. $\mathrm{VLE}_{\mathrm{f}} / \mathrm{RLE} \geq 1.0$ ). These load factors are 2.02, 1.35,

542 and 1.93 for the Best Selection and governing MDOT and AASHTO Trucks, respectively. For 
543 each model, the governing bridge (i.e. that which produced least reliability, governing the

544 required minimum load factor) case was a side-by-side box beam bridge $6 \mathrm{~m}$ long; note that the

545 values given in the Figure represents the governing case of all bridge girder types considered

546 (steel, prestressed concrete, steel, side by side and spaced box beams) for a particular span. As

547 shown, most consistency as well as closeness to the RLE, and thus target reliability index, can be

548 obtained with the RBDO-developed model. This is particularly so when compared to the MDOT

549 rating trucks, which result in significant conservatism in rating for the shorter spans, where the

550 highest $\left(\mathrm{VLE}_{\mathrm{f}} / \mathrm{RLE}\right)$ ratio reached approximately 1.85 at the $18 \mathrm{~m}$ span. Although not as severe,

551 the AASHTO trucks also showed significant discrepancy at the lower spans, with a (VLEf $/$ RLE)

552 ratio of about 1.20 at the $18 \mathrm{~m}$ span. Figure 6 also shows that the single Best Selection Truck is

553 nearly as good as the RBDO model, producing discrepancies much less than existing MDOT and

554 AASHTO models. Results from all rating models shown in Figure 6 are quantified in Table 4,

555 where the minimum $\left(\beta_{\min }\right)$ and maximum $\left(\beta_{\max }\right)$ reliability indices corresponding to the largest

556 discrepancies shown in Figure 6 are given, as well as the coefficient of variation of reliability

557 index $\left(V_{\beta}\right)$ from all girders considered across all bridge types and span is given. To fairly

558 compare results, a best possible outcome is also given, provided that the same rating load model

559 would be used for all bridge types, as is expected in rating practice. This is given as the "Exact

560 (using RLE)" result. For this case, the results presented in the table correspond to a (VLE/RLE)

561 ratio of 1.0 for all spans on Figure 6. Notice that this best possible outcome does not produce

562 identical reliability values across all cases, however, as the range of reliability index for the

563 "Exact" case actually varies from 2.5 - 3.95, as shown in Table 4. This occurs because there

564 are multiple bridge types analyzed when each span is considered, and because different

565 uncertainties in resistance and load distribution are associated with these different bridge types, a 

different reliability index in rating will be achieved if the same load model is used to rate these different types of structures (Eamon and Siavashi 2018). In the results shown, as noted above, it

568 is assumed that the same rating truck will be used for all bridge types of a given span; i.e. the

569 rating agency would not use one type of rating truck for steel girders, and a different rating truck 570 for concrete girders, etc. Because the same rating model is used for all bridge types, only one of 571 these types will produce the largest RLE, and the others, with lower RLE, will be rated 572 somewhat more conservatively. It is this governing RLE case that is shown on Figure 6 as a 573 function of span. Thus, a variation in reliability index, as shown in Table 4, results even for the 574 "Exact" case, which practically cannot be improved further.

As shown in Table 4, the RBDO model produces results nearly identical to the Exact

576 model, with only a slightly higher average reliability index among all cases $\left(\beta_{\text {ave }}\right.$, Exact $=2.83$;

$\left.577 \beta_{\text {ave }}, \mathrm{RBDO}=2.84\right)$. The Best Selection Truck produces results nearly as good, with only a 578 slightly higher $\beta_{\max }$ and $\beta_{\text {ave }}$ than the Exact result $\left(\beta_{\max } ; 3.96\right.$ vs 3.95 and $\beta_{\text {ave }} ; 2.88$ vs 2.83$)$.

579 More notably, the COV of reliability indices for all bridge cases is identical (to 2 decimal 580 places) among the Exact, RBDO, and Best Selection results, of 0.13. When the existing MDOT 581 trucks are considered (with the required load factor (LF) applied), it can be seen that the 582 maximum, average, as well as COV of reliability index are markedly greater than the ideal 583 solution. In comparison, as shown in Table 4, the AASHTO Trucks produced surprisingly good 584 results for moment effect overall, while although worse than the RBDO and Best Selection 585 solutions, results were relatively close, with the AASHTO model (once the required minimum 586 load factor of 1.93 was applied) producing $\beta_{\max }$ and $\beta_{\text {ave }}$ only 5-7\% higher than the ideal solution, 587 and COV increasing from 0.13 to 0.15 . The relative accuracy of this model did not hold for 588 shear results, however, as discussed below. In comparison, the MDOT model (with required load 
589 factors) produced a much worse solution, with $\beta_{\max }, \beta_{\text {ave }}$, and COV significantly higher than the 590 alternative models.

Shear results are given in Figure 7 and Table 5. The same bridge that governs for moment did so for shear as well (6 m, side by side box beam), with minimum required load 593 factors of $1.79,1.40$, and 2.40 for the Best Selection, MDOT, and AASHTO Trucks, 594 respectively. In the figure, some interesting results are shown, where although for moment, the 595 most conservatively rated span for the AASHTO and MDOT models is $18 \mathrm{~m}$ (prestressed 596 concrete box beams with $3.6 \mathrm{~m}$ girder spacing) and a $24 \mathrm{~m}$ span of the same bridge type for the 597 Best Selection truck, for shear, the most conservatively rated span is $30 \mathrm{~m}$ for all models. 598 Moreover, discrepancies with the MDOT model decreased, where the maximum load ratio $599(\mathrm{VLE} / \mathrm{RLE})$ dropped from about 1.85 for moment to 1.56 for shear, but discrepancies for the 600 AASHTO model increased, with maximum load ratios changing from about 1.20 to 1.35. 601 Similarly, results for the Best Selection Truck worsened (where the maximum load ratio 602 increased from about 1.03 to 1.10 ), whereas the RBDO solution for shear produced nearly the 603 same accuracy as for moment, with discrepancies within $1 \%$. Note that although the Best 604 Selection result worsened for shear, it remains a substantially better solution compared to the 605 AASHTO and MDOT shear models.

606 As shown in Table 5, the range of shear reliability index for the exact solution has 607 increased somewhat from that of moment, with $\beta_{\max }$ and $\beta_{\text {ave }}$ increasing from 3.95 to 4.20 and 6082.83 to 2.90, respectively. The variance of all results has decreased, however, from 0.13 to 0.10, 609 with both the RBDO and Best Selection models producing nearly identical solutions, although a 610 slight increase in occurs $\beta_{\text {ave }}$ with the Best Selection Truck, from 2.88 for moment to 3.00 for 611 shear. As with moment results, COV for shear results for the Best Selection Truck (0.10) 
612 matched that of the RBDO and exact solutions. For shear, the AASHTO model considerably

613 worsened when compared to moment results, producing a substantially higher $\beta_{\text {max }}, \beta_{\text {ave }}$, as well

614 as COV as compared to the exact solution, with values of $4.97,3.33$, and 0.14 , respectively. In

615 this case, AASHTO results are similar to those found from the MDOT model, which again

616 produced worst results overall.

617 It should be noted that the reliability index and RLE results are not based on nor are 618 significantly impacted by any single maximum WIM data vehicle load effect. In fact, removing 619 any single, or numerous single vehicles, including the best selection vehicle, from the WIM data 620 will have no practical impact on the computed live load random variable $(L L)$ parameters shown 621 in Table 2. Rather, these values are based on a load projection using hundreds to thousands of 622 vehicle load effects, the governing of which are from multiple vehicles together (in following 623 and side-by-side configurations; see Eamon and Siavashi 2018 and Eamon et al. 2016). That is, 624 the Best Selection vehicle does not represent a governing, nor even typical, load effect. Rather, 625 its configuration best-replicates the pattern of projected load effects across the different spans 626 considered.

Although results were shown for the specific traffic data described above (i.e. Michigan 628 legal and routine permit vehicles), to verify the applicability of the Best Selection method, this 629 approach and the RBDO procedure were repeated on a set of 78 million vehicles collected from 630 Michigan that meet the Federal Bridge Formula (FHWA 2015). Significantly more restrictive 631 than the originally considered Michigan database of legal and extended permit vehicles, this new 632 set of vehicles would meet the legal requirements common to many states. Application of Eq. 7 633 (with $\mathrm{k}=0.10$ ) reduced this set of vehicles to approximately 740,000 for further consideration. 
634 Comparing the results of both vehicle databases, nearly identical results were found using the

Best Selection approach in terms of closeness to the ideal RBDO solution.

Although this Best Selection approach was found to be effective, several limitations should be noted. First, as potential solutions are found within the collected vehicle database, a reasonably large pool of vehicles must be available. Although 2.2 million vehicles were used in this study (i.e. after the application of Eq. 7), it was found that nearly as good results (with a difference of a few percent) could be obtained using only approximately $1 / 6^{\text {th }}$ of this vehicle pool, or about 350,000 vehicles. However, as the size of the database decreases, correspondingly worse solutions will result. Second, the data set used in the Best Selection process should be representative of the entire pool for which the load model is to be developed. That is, conducting the best selection on data from a single WIM site rather than a series of sites throughout the state may be problematic, as results may be locally biased, potentially missing the most effective solutions. Third, there is inherent uncertainty as to how close the Best Selection result will be to the ideal solution. Fortunately, error is readily quantifiable by comparing results to the required load effects (RLE); unacceptably large errors may indicate the need to implement the more costly RBDO method.

Finally, further note that the RLE values can be readily determined using the relatively simple reliability analysis described in the corresponding section above. Direct use of the RLE would not only allow for an exact reliability-based rating assessment for each structure, but would avoid any additional computational effort associated with further load model development. Although theoretically ideal, this approach may be problematic in practice. In particular, existing rating and posting procedures used by most state DOTs are based on a framework that uses representative vehicles. This includes the use of specialized rating software 
657 that requires vehicle configurations as inputs, the desire for compatibility with the vehicle-based

658 format of existing rating standards, as well as the desire to minimize the need to use different

659 loads, vehicles, and/or factors for different spans and bridge types. Thus, the direct use of RLE

660 values may be difficult to implement in current practice, and hence the alternative vehicle-based

661 alternatives considered here, which were recently proposed to MDOT and are currently under

662 consideration.

664 Summary and Conclusion

The potential effectiveness of using RBDO and an alternative method to develop a

666 reliability-based load rating model considering state-specific traffic was studied.

667 It was found that the RBDO procedure could develop a load model more effective than

668 the existing rating models suggested by AASHTO as well as the significantly more complex,

669 state-specific DOT model. In particular, a modest improvement was achieved over the

670 AASHTO model for moment effects, while a significant improvement was made for shear, as

671 well as a significant improvement for both moment and shear effects from the DOT model.

672 However, for the RBDO process to be feasible, it was found that reduction of computational

673 effort as much as possible was essential. This was effectively done using a slightly modified,

674 non-iterative reliability approach to allow use of a single-loop RBDO procedure. The RBDO

675 solution produced final results nearly identical to a theoretically ideal solution.

In comparison, a Best Selection Approach was studied, where it was proposed to select a

677 vehicle directly from the WIM data that minimizes discrepancies in load effects. It was found

678 that this method produced nearly identical results as the RBDO solution for moment rating and

679 only slightly worse results for shear rating. It was further found that more complicated rating 
680 models are not necessarily most effective. The most simple vehicle model studied, that 681 developed from the Best Selection Approach, uses only a single rating vehicle for moment 682 effects and another vehicle for shear effects, while it produced significantly more consistent 683 results overall when compared to the multiple-vehicle AASHTO and MDOT alternative models.

684 Given that the Best Selection Approach represents a large reduction in problem 685 complexity and computational cost as the RBDO solution, as well as provides a realistic (actual) 686 load rating vehicle, it is recommended for future consideration for state-specific load rating 687 model development. 


\section{References}

AASHTO. (2017). LRFD Bridge Design Specifications, 8th Ed., Washington, D.C.

AASHTO (2002). Standard specifications for highway bridges, 17th Ed., Washington, DC.

AASHTO (2018). Manual for bridge evaluation, 3rd Ed., Washington, D.C.

AASHTO (2003). Manual for condition evaluation and load and resistance factor rating (LRFR) of highway bridges. AASHTO, Washington, D.C.

Agarwal, H., Mozumder, C., Renaud, J., and Watson, L. (2007) “An inverse-measure-based unilevel architecture for reliability-based design optimization." Structural and Multidisciplinary Optimization; 33(3): 217-227.

Aoues, Y., and Chateauneuf, A. (2010) "Benchmark study of numerical methods for reliabilitybased design optimization." Structural and Multidisciplinary Optimization 41: 277-294.

Anitori, G., Casas, J.R., and Ghosn, M. (2017) "WIM-Based Live-Load Model for Advanced Analysis of Simply Supported Short-and Medium-Span Highway Bridges.” Journal of Bridge Engineering, 10.1061/(ASCE)BE.1943-5592.0001081.

Basha, B., and Sivakumar, B. (2010) "Optimum design of bridge abutments under seismic conditions: reliability-based approach." ASCE Journal of Bridge Engineering; 10.1061/(ASCE)1084-0702(2010)15:2(183), 183-195.

Behnam, B., and Eamon, C. (2013) "Reliability-based design optimization of concrete flexural members reinforced with ductile FRP bars." Construction and Building Materials 47:942-950. 
Chen, X., Hasselman, T. K., and Neill, D. J. (1997) "Reliability based structural design optimization for practical applications." Proceedings, 38th AIAA SDM Conference

Choi, K., Tu, J., and Park Y. (2001) "Extensions of design potential concept for reliability-based design optimization to nonsmooth and extreme cases." Structural and Multidisciplinary Optimization 22: 335-350.

Curtis R, and Till R. (2008) "Recommendations for Michigan specific load and resistance factor design loads and load and resistance factor rating procedures." MDOT Research Report R-1511, Michigan Department of Transportation.

Du, X., and Chen, W. (2004) "Sequential optimization and reliability assessment method for efficient probabilistic design.” ASME Journal of Mechanical Design 126(2): 225-233.

Eamon, C., Kamjoo, V., and Shinki, K. (2016) "Design live-load factor calibration for Michigan highway bridges.” ASCE Journal of Bridge Engineering; 10.1061/(ASCE)BE.19435592.0000897, 04016014.

Eamon, C. D., and Siavashi, S. (2018). "Developing Representative Michigan Truck Configurations for Bridge Load Rating.” Report Number SPR-1640. Michigan. Dept. of Transportation. Research Administration.

Enevoldsen, I., and Sorensen, J. (1994) "Reliability-based optimization in structural engineering." Structural Safety 15: 169-196.

Fan, S. K. S., Chang, Y. J., and Aidara N. (2013). "Nonlinear profile monitoring of reflow process data based on the sum of sine functions." Quality and Reliability Engineering International, 29(5), 743-758. 
730 Federal Highway Administration (2015). "Bridge Formula Weights." US Department of Transportation, Office of Freight Management and Operations. FHWA-HOP-06-105.

Frangopol, D. M. (1995) "Reliability-based optimum structural design." Probabilistic structural mechanics handbook, 352-387

Garcia-Segura, T., Yepes, V., Frangopol, D., and Yang, D. (2017) “Lifetime reliability-based optimization of post-tensioned box-girder bridges". Engineering Structures; 145: 381391.

Ghosn M, Sivakumar B, and Miao F. (2011) "Load and resistance factor rating (LRFR) in NYS”, Final Report. NYSDOT Report C-06-13, New York State Department of Transportation.

Grandhi, R. V., and Wang L. (1998) "Reliability-based structural optimization using improved two-point adaptive nonlinear approximation." Finite Elements in Analysis and Design; 29: $35-48$.

Hao, H., \& Xia, Y. (2002). "Vibration-based damage detection of structures by genetic algorithm." Journal of Computing in Civil Engineering, 16, no. 3: 222-229.

Kamjoo, V. and Eamon, C. (2018). "Reliability-Based Design Optimization of a Vehicular Live Load Model.” Engineering Structures, no. 168: 799-808.

Karaboga, D., and Basturk, B. (2007) “A powerful and efficient algorithm for numerical function optimization: artificial bee colony (ABC) algorithm.” Journal of global optimization; 39(3): 459-471.

Kennedy, J. (2011) "Particle swarm optimization. Encyclopedia of machine learning” Springer US. 
751 Kharmanda, G., Mohamed, A., and Lemaire, M. (2002) "Efficient reliability-based design

752 optimization using a hybrid space with application to finite element analysis." Structural and Multidisciplinary Optimization 24, no. 3: 233-245.

754 Kharmanda, G., and Olhoff, N. (2007) "Extension of optimum safety factor method to nonlinear 755

756 reliability-based design optimization." Structural and Multidisciplinary Optimization 34, no. 5: 367-380.

Kirjner-Neto, C., Polak, E., and Der Kiureghian, A. (1998) “An outer approximations approach to reliability-based optimal design of structures." Journal of optimization theory and applications 98, no. 1: 1-16.

760 761 762 763 764 765 766 767 768 769 770 771
Kirkpatrick, S. (1984) “Optimization by simulated annealing: Quantitative studies.” Journal of statistical physics 34, no. 5-6: 975-986.

Koch, P., and Kodiyalam, S. (1999) "Variable complexity structural reliability analysis for efficient reliability-based design optimization.” In 40th Structures, Structural Dynamics, and Materials Conference and Exhibit, p. 1210.

Konak, A., Coit, D. W., and Smith, A. E. (2006). "Multi-objective optimization using genetic algorithms: A tutorial.” Reliability Engineering \& System Safety, 91, no. 9: 992-1007.

Koumousis, V. K., and Georgiou, P. G. (1994) “Genetic algorithms in discrete optimization of steel truss roofs." Journal of Computing in Civil Engineering 8, no. 3: 309-325.

Kwon, O. S., Orton, S., Salim, H., Kim, E. and Hazlett, T. (2010) "Calibration of the live load factor in LRFD design guidelines." MODOT Report ORI1-003, Missouri Department of Transportation. 
772 Kusano, I., Baldomir, A., and Jurado, J. A., Hernández S. (2014) "Reliability based design

773

774

775

776

777

778

779

780

781

782

783

784

785

786

787

788

789

790

791

792

optimization of long-span bridges considering flutter." Journal of Wind Engineering and Industrial Aerodynamics 135: 149-162.

Lee, C. E., and Souny-Slitine, N. (1998) "Final research findings on traffic-load forecasting using weigh-in-motion data.” Report 987-7, Center for Transportation Research Bureau of Engineering Research, The University of Texas at Austin.

Man, K. F., Tang, K. S., \& Kwong, S. (1996). “Genetic algorithms: concepts and applications [in engineering design]”. IEEE transactions on Industrial Electronics, 43, no. 5: 519-534.

MDOT Bridge Analysis Guide (2009), 2005 Ed, with 2009 Interim Update, Parts 1 and 2. Michigan Department of Transportation Construction and Technology Support Area.

Mohsine, A., Kharmanda, G., and El-Hami, A. (2006) "Improved hybrid method as a robust tool for reliability-based design optimization.” Structural and Multidisciplinary Optimization 32, no. 3: 203-213.

Nakib R. (1997) “Deterministic and reliability-based optimization of truss bridges." Computers \& structures 65 , no. 5: 767-775.

Negrão, J. H., and Simões L. M. (2004) "Reliability-based optimum design of cable-stayed bridges." Structural and Multidisciplinary Optimization 28, no. 2-3: 214-220.

Nowak AS. (1999) “Calibration of LRFD bridge design code.” NCHRP Report 368, Transportation Research Board, Washington, D.C.

Pelphrey, J., and Higgins, C. (2006) “Calibration of LRFR live load factors using weigh-inmotion data." No. FHWA-OR-RD-06-17. 
793 Qu, X., and Haftka, R. T. (2004) "Reliability-based design optimization using probabilistic sufficiency factor.” Structural and Multidisciplinary Optimization 27, no. 5: 314-325.

795 Rackwitz, R., and Flessler, B. (1978) “Structural reliability under combined random load 796 sequences.” Computers \& Structures 9, no. 5: 489-494.

797 Rais-Rohani, M., Solanki, K., Acar, E., and Eamon, C. (2010) "Shape and sizing optimization of 798 automotive structures with deterministic and probabilistic design constraints." International Journal of Vehicle Design 54, no. 4:309-338.

Rais-Rohani, M., and Xie, Q. (2005) “Probabilistic structural optimization under reliability, 801 manufacturability, and cost constraints.” AIAA journal 43, no. 4: 864-873.

802 803 804 805 806 807 808 809 810 811 812 813
Saad, L., Aissani, A., Chateauneuf, A., and Raphael, W. (2016) "Reliability-based optimization of direct and indirect LCC of RC bridge elements under coupled fatigue-corrosion deterioration processes.” Engineering Failure Analysis 59: 570-587.

Sivakumar, B., Ghosn, M., and Moses, F. (2011). "Protocols for collecting and using traffic data in bridge design” NCHRP Report 683, Transportation Research Board, Washington, D.C.

Soler, J., Gómez, M., and Rodellar, J. (2012) “Goroso: Feedforward control algorithm for irrigation canals based on sequential quadratic programming.” Journal of Irrigation and Drainage Engineering 139, no. 1: 41-54.

Tabatabai, H., Zhao, J., and Lee, C. W. (2000) “ Statistical analysis of heavy truck loads using Wisconsin Weigh-IN-Motion data project 01-02”. No. CFIRE 01-02.

Tang, K.S, Man, K.F, Kwong, S. (1996) “Genetic algorithms and their applications” IEEE Signal Processing Magazine, 13, no. 6. 
814 Thoft-Christensen, P. (2009) "On reliability based optimal design of concrete bridges.” In Advanced Technology in Structural Engineering, pp. 1-8.

816 Thompson, M., Eamon C. D., and Rais-Rohani, M. (2006) "Reliability-based optimization of 817 fiber-reinforced polymer composite bridge deck panels.” Journal of structural $818 \quad$ engineering 132, no. 12: 1898-1906.

819 Tu, J., Choi K.K., and Park, Y.H. (1999) “A new study on reliability-based design 820 optimization.” Journal of mechanical design 121, no. 4: 557-564.

821 Turan, K. H, and Yanmaz, A.M. (2011) "Reliability-based optimization of river bridges using 822 artificial intelligence techniques." Canadian Journal of Civil Engineering 38, no. 10:

823 1103-1111.

824

Vanderplaats, G. N. (1999) “Numerical optimization techniques for engineering design,

825 Research \& Development.”, Inc., Colorado Springs, CO.

Yang, G., Zhang, A.F., and Li, X.K. (2011) “Optimization Design Method of Steel Truss Girder Bridge Reliability." Advanced Materials Research, vol. 243, pp. 1826-1829. Trans Tech Publications.

829 Yang, R. J., and Gu, L. (2004) "Experience with approximate reliability-based optimization 830 methods." Structural and Multidisciplinary Optimization 26, no. 1-2: 152-159.

831 Youn, B. D., and Choi, K.K. (2004) "Selecting probabilistic approaches for reliability-based 832 design optimization.” AIAA journal 42, no. 1: 124-131.

Zou, T., and Mahadevan, S. “A direct decoupling approach for efficient reliability-based design 834 Structural and Multidisciplinary Optimization 31, no. 3 (2006): 190. 


\section{List of Tables}

Table 1. Michigan Legal and Routine Permit Vehicle Filtering Criteria.

Table 2. Random Variables.

Table 3. Coefficients for Sum of Sines Model.

Table 4. Comparison of Moment Design Load Models.

Table 5. Comparison of Shear Design Load Models.

\section{List of Figures}

Fig. 1. AASHTO Rating Trucks $(\mathrm{kN}, \mathrm{m})$.

Fig. 2. Governing MDOT Rating Trucks (kN, m).

Fig. 3. Example Comparison of Load Effect Ratios Using Best Selection Method.

Fig. 4. Best Selection Approach Trucks (kN, m).

Fig. 5. Vehicle to Required Load Effect Ratios for Moment.

Fig. 6. Vehicle to Required Load Effect Ratios for Shear. 
Table 1. Michigan Legal and Routine Permit Vehicle Filtering Criteria.

\begin{tabular}{ll}
\hline Vehicle Type & Criteria \\
\hline Legal, & For axles spaced $\geq 2.75 \mathrm{~m}$, axles $\leq 80 \mathrm{kN}$ \\
$\mathrm{GVW}>356 \mathrm{kN}$ & For axles spaced from $1-2.7 \mathrm{~m}$, axles $\leq 58 \mathrm{kN}$ \\
& For axles spaced $<1 \mathrm{~m}$, axles $\leq 40 \mathrm{kN}$ \\
& $2 \leq$ Number of axles $\leq 11$ \\
& Vehicle Length $\leq 29 \mathrm{~m}$ \\
\hline Legal, & Any individual axle $\leq 89 \mathrm{kN}$ \\
& Sum of tandem axles $\leq 151 \mathrm{kN}$ \\
$\mathrm{GVW}<356 \mathrm{kN}$ & $2 \leq$ Number of axles $\leq 11$ \\
& Vehicle Length $\leq 29 \mathrm{~m}$ \\
\hline Permit & Length $\leq 26 \mathrm{~m}$ \\
$($ Construction $) *$ & Any axle $\leq 107 \mathrm{kN}$ \\
& GVW $\leq 667 \mathrm{kN}$ \\
& $2 \leq$ Number of axles $\leq 11$ \\
& Vehicle Length $\leq 26 \mathrm{~m}$ \\
\hline Various types of permits exist, depending on vehicle use category and cargo type. Permits for construction \\
vehicles are generally most permissive and govern load effects.
\end{tabular}


Table 2. Random Variables.

\begin{tabular}{lccc}
\hline Random Variable & \multicolumn{2}{c}{ Bias Factor } & COV \\
\hline Resistance RVs & $R$ & $\lambda$ & \\
\hline Prestressed Concrete, Moment & & 1.05 & 0.075 \\
Prestressed Concrete, Shear & & 1.15 & 0.14 \\
Reinforced Concrete, Moment & & 1.14 & 0.13 \\
Reinforced Concrete, Shear & & 1.20 & 0.155 \\
Steel, Moment & 1.12 & 0.10 \\
Steel, Shear & & 1.14 & 0.105 \\
\hline Load RVs & & \\
\hline Vehicle Live Load, Moment & $L L$ & $1.07-2.08^{2}$ & $0.16-0.27^{3}$ \\
Vehicle Live Load, Shear & $L L$ & $1.0-1.64^{2}$ & $0.16-0.30^{3}$ \\
Live Load Impact Factor & $I M$ & $1.13 ; 1.10^{4}$ & $0.09 ; 0.055^{4}$ \\
Vehicle Load Distribution Factor & $D F$ & $0.72-0.99$ & $0.11-0.18$ \\
Dead Load, Prefabricated & $D_{p}$ & 1.03 & 0.08 \\
Dead Load, Site-Cast & $D_{s}$ & 1.05 & 0.10 \\
Dead Load, Wearing Surface & $D_{w}$ & mean $89 \mathrm{~mm}$ & 0.25 \\
\hline
\end{tabular}

1. Assumes shear stirrups present.

2. Bias factor is given as the ratio of mean load effect to the nominal Michigan legal rating truck load effect; varies as a function of span.

3. Includes uncertainties from data projection, site, WIM data, impact factor, and load distribution; varies as a function of span.

4. Bias factor is given as a multiple of static LL, such that the total vehicular load effect is LL*bias IM . First values refer to single lane load effects; second values refer to two-lane load effects. 
Table 3. Coefficients for Sum of Sines Model.

\begin{tabular}{lccccccccc}
\hline Load Effect & \multicolumn{10}{c}{ Parameter } \\
& $a_{1}$ & $b_{1}$ & $c_{1}$ & $a_{2}$ & $b_{2}$ & $c_{2}$ & $a_{3}$ & $b_{3}$ & $c_{3}$ \\
\hline Moment & 8556 & 0.015 & -0.621 & 4879 & 0.022 & 2.07 & 295 & 0.053 & 1.91 \\
Shear & 244 & 0.002 & .021 & 113 & 0.002 & 6.30 & 4.59 & 0.062 & -1.67 \\
\hline
\end{tabular}


Table 4. Comparison of Moment Design Load Models.

\begin{tabular}{lccccc}
\hline Design Load & $\begin{array}{c}\text { Load } \\
\text { Factor }\end{array}$ & $\beta_{\min }$ & $\beta_{\max }$ & $\beta_{\text {average }}$ & COV \\
\hline Exact (using RLE) & - & 2.50 & 3.95 & 2.83 & 0.13 \\
\hline RBDO Load Model & - & 2.50 & 3.95 & 2.84 & 0.13 \\
\hline Best Selection Truck & 2.02 & 2.50 & 3.96 & 2.88 & 0.13 \\
\hline MDOT Trucks (current LF) & varies $^{1}$ & 2.13 & 5.52 & 3.74 & 0.20 \\
MDOT Trucks (required LF) & 1.35 & 2.50 & 5.74 & 4.09 & 0.18 \\
\hline AASHTO Trucks (current LF) & 1.80 & 2.25 & 3.85 & 2.84 & 0.15 \\
AASHTO Trucks (required LF) & 1.93 & 2.50 & 4.14 & 3.05 & 0.15 \\
\hline
\end{tabular}

1. See Figure 2 for load factors. 
Table 5. Comparison of Shear Design Load Models.

\begin{tabular}{lccccc}
\hline Design Load & $\begin{array}{c}\text { Load } \\
\text { Factor }\end{array}$ & $\beta_{\min }$ & $\beta_{\max }$ & $\beta_{\text {average }}$ & COV \\
\hline Exact (using RLE) & - & 2.50 & 4.20 & 2.90 & 0.10 \\
\hline RBDO Load Model & - & 2.50 & 4.25 & 2.91 & 0.10 \\
\hline Best Selection Truck & 1.79 & 2.50 & 4.20 & 3.00 & 0.10 \\
\hline MDOT Trucks (current LF) & varies $^{1}$ & 2.10 & 4.67 & 3.22 & 0.14 \\
MDOT Trucks (required LF) & 1.40 & 2.50 & 5.05 & 3.55 & 0.14 \\
\hline AASHTO Legal Trucks (current LF) & 1.80 & 1.70 & 3.85 & 2.67 & 0.13 \\
AASHTO Legal Trucks (required LF) & 2.40 & 2.50 & 4.97 & 3.33 & 0.14 \\
\hline
\end{tabular}

1. See Figure 2 for load factors. 


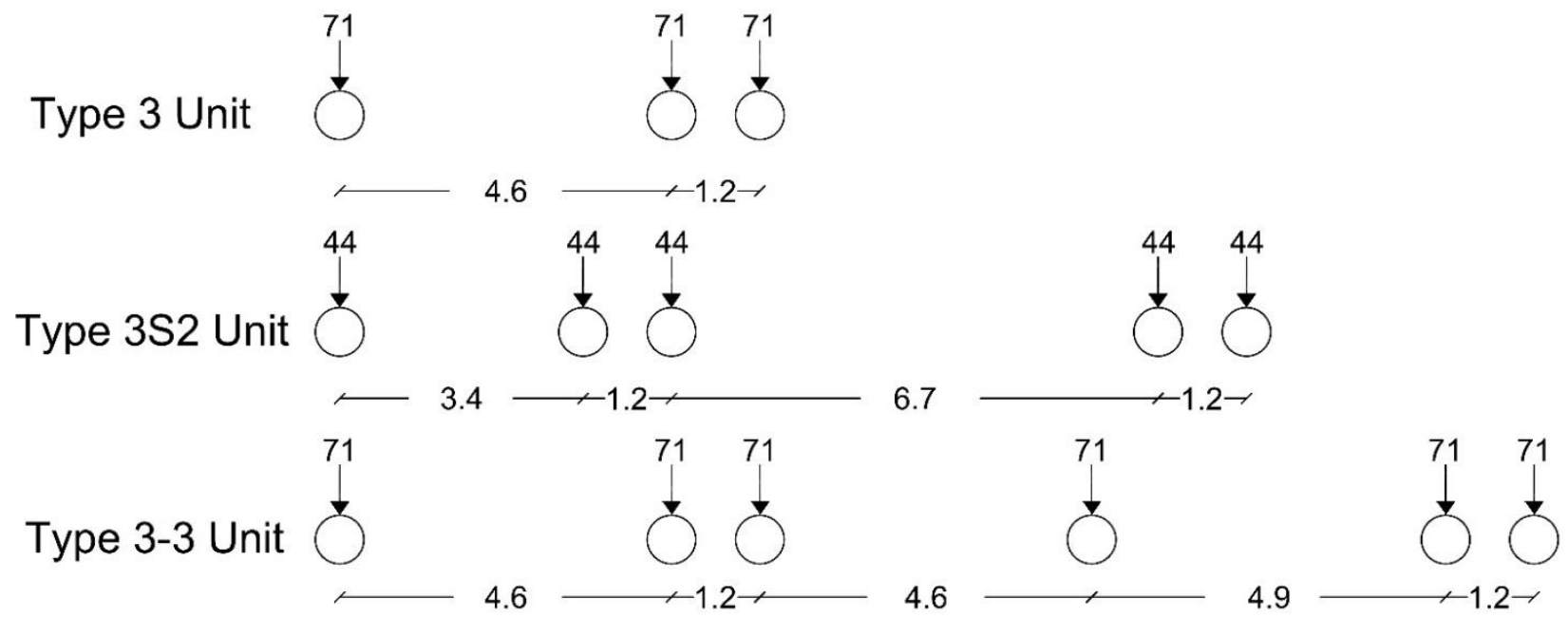

Figure 1. AASHTO Rating Trucks (kN, m). 
Truck No. $14(\mathrm{LF}=1.31)$ Governs Span:12 m

Truck No. $16(\mathrm{LF}=1.28)$ Governs Span: 6 m

Truck No. $17(\mathrm{LF}=1.21)$ Governs Span: 18-30 m

Truck No. $18(\mathrm{LF}=1.20)^{*}$ Governs Span: 36-48 m

Truck No. $25(\mathrm{LF}=1.16)^{\star *}$ Governs Span: 36-60 m
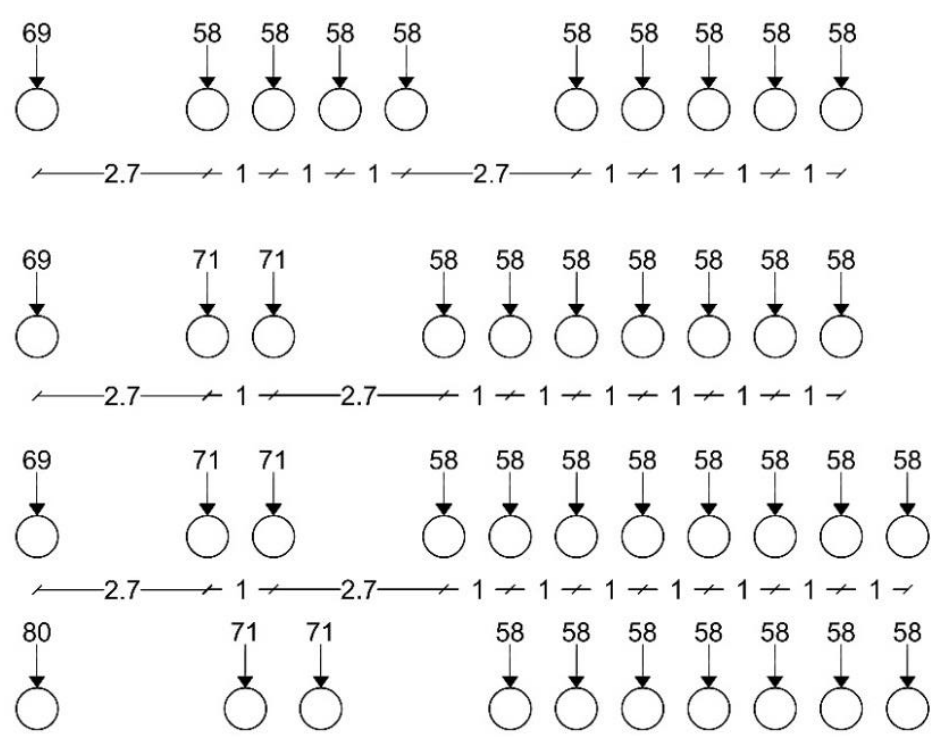

$3.4 \longrightarrow 1.2+3$
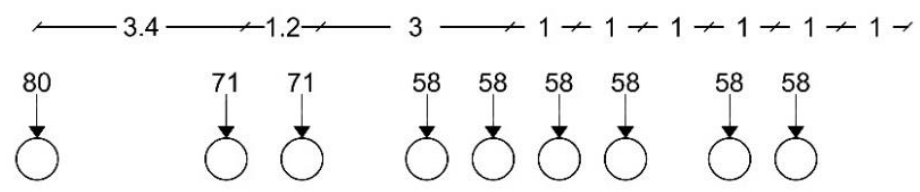

3

* Truck 18 governs for shear.

** Truck 25 governs for shear from 54-60 m.

Figure 2. Governing MDOT Rating Trucks (kN, m). 


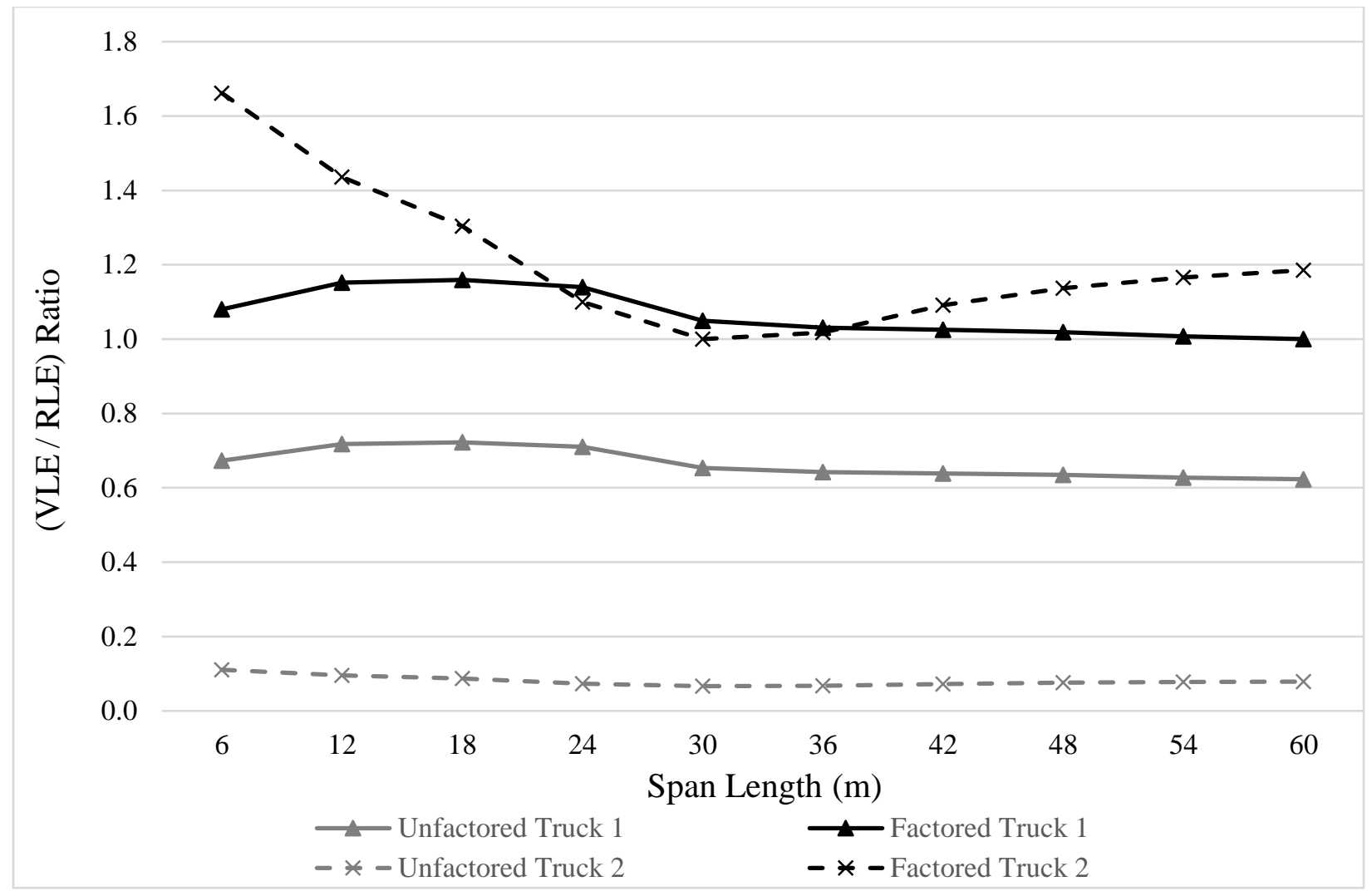

Figure 3. Example Comparison of Load Effect Ratios Using Best Selection Method. 


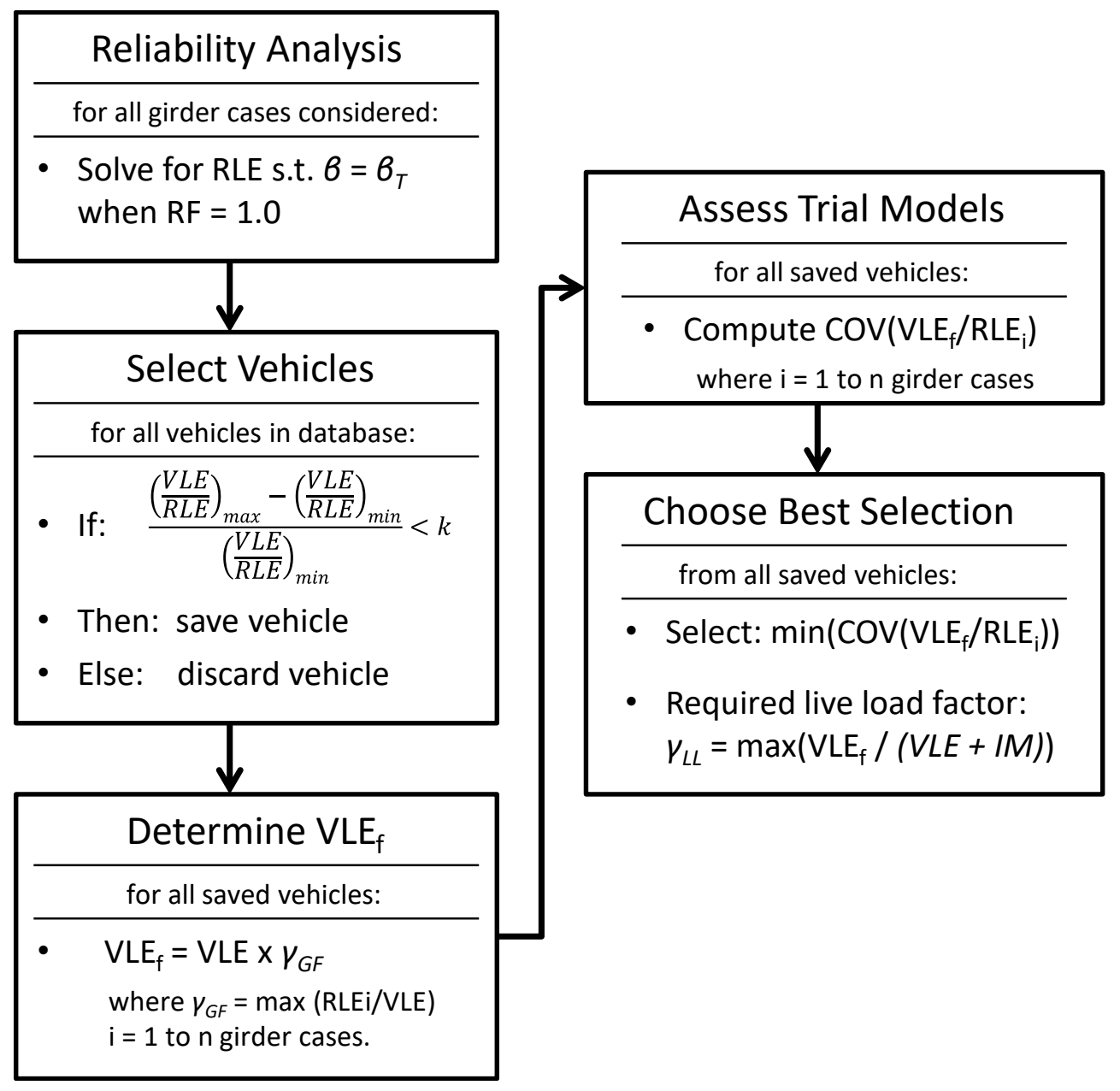

Figure 4. Best Selection Method Flowchart. 


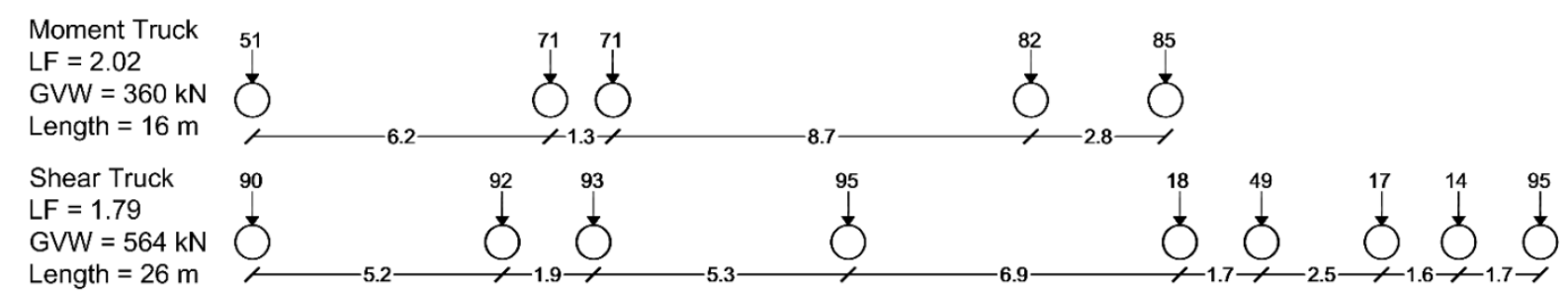

Figure 5. Best Selection Approach Trucks (kN, m). 


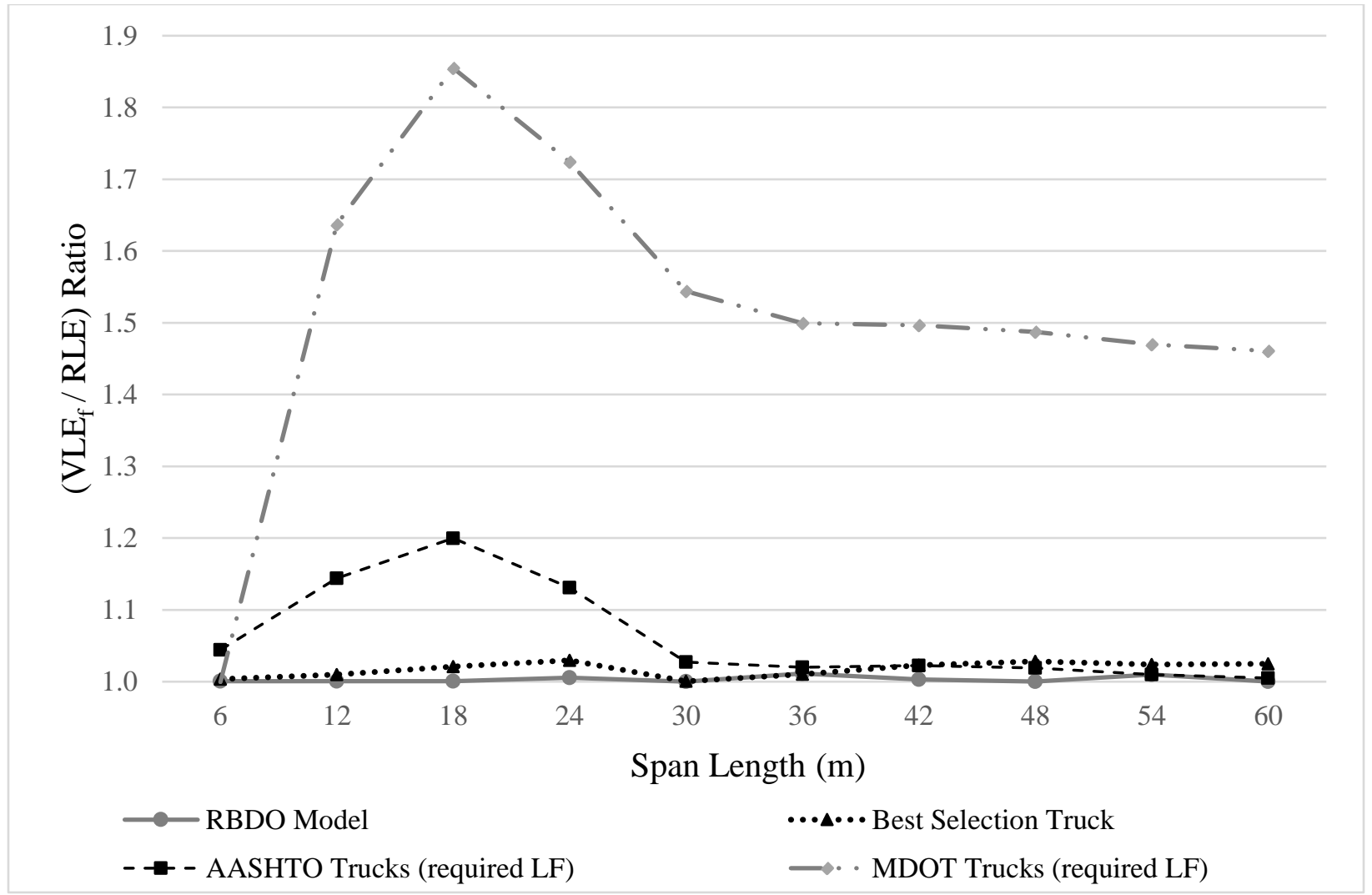

Figure 6. Vehicle to Required Load Effect Ratios for Moment. 


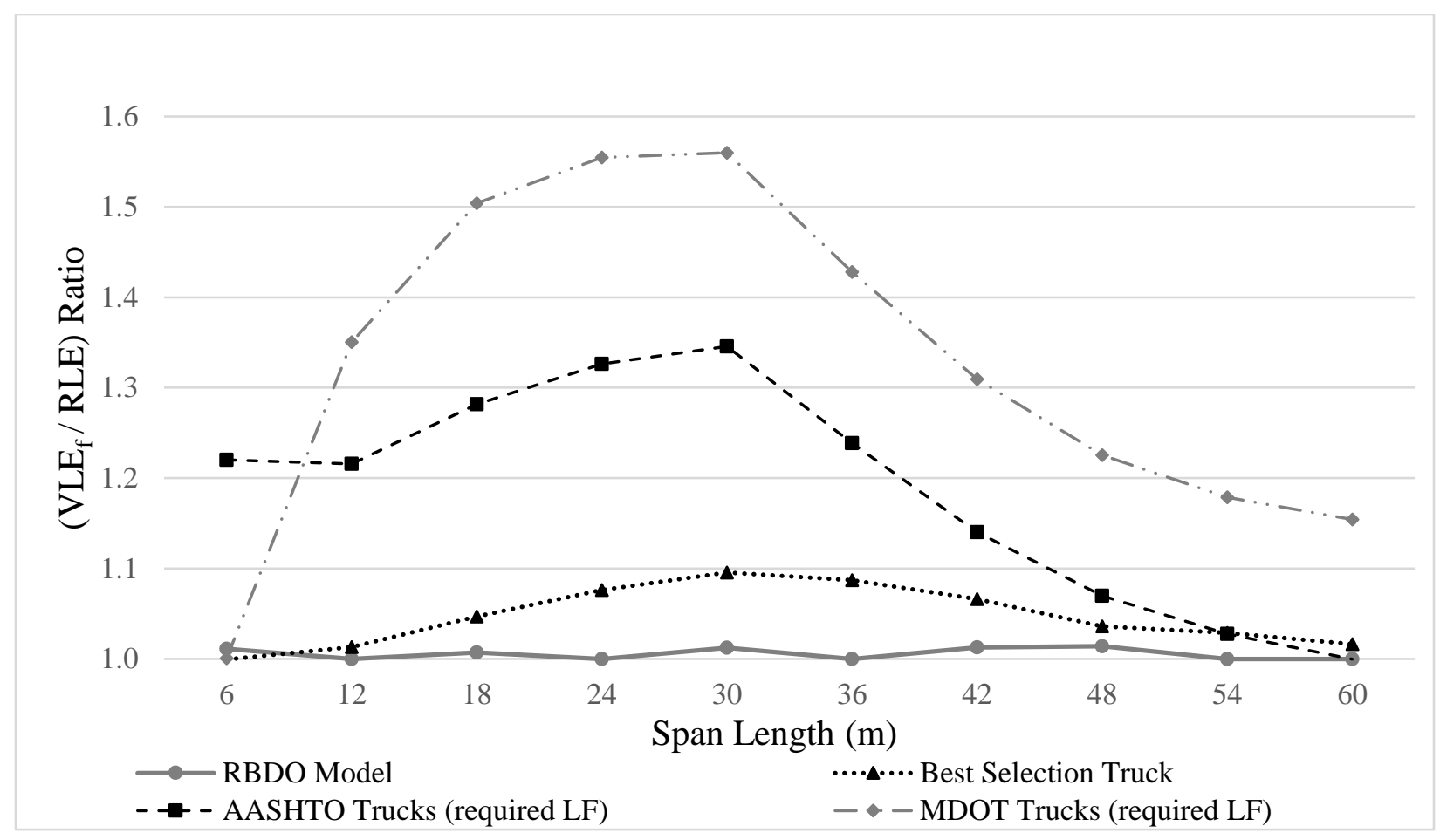

Figure 7.Vehicle to Required Load Effect Ratios for Shear. 